\title{
Light Emitting Single-Crystalline Silicon Wafers Implanted with V and III Group Ions
}

\author{
F. Komarov ${ }^{a}$, L. Vlasukova ${ }^{a}$, O. Milchanin $^{a}$, M. Greben $^{a, *}$, I. Parkhomenko ${ }^{a}$, \\ A. MUdRYi ${ }^{b}$, E. WendLER $^{c}$ AND P. ZuKOWsKi ${ }^{d}$ \\ ${ }^{a}$ Belarusian State University, Nezavisimosti ave. 4, 220030 Minsk, Belarus \\ ${ }^{b}$ Scientific and Practical Materials Research Center, National Academy of Sciences of Belarus \\ P. Brovki Str. 17, 220072 Minsk, Belarus \\ ${ }^{c}$ Institut für Festkörperphysik, Friedrich-Schiller-Universität Jena, Max-Wien-Platz 1, D-07743 Jena, Germany \\ ${ }^{d}$ Lublin University of Technology, Nadbystrzycka 38d, 20-618 Lublin, Poland
}

\begin{abstract}
Compound semiconductor nanocrystals (InAs, InSb, GaSb) were successfully synthesized in single crystalline $\mathrm{Si}$ by high fluence ion implantation at $500{ }^{\circ} \mathrm{C}$ followed by high-temperature rapid thermal annealing or conventional furnace annealing at $900-1100{ }^{\circ} \mathrm{C}$. Rutherford backscattering spectrometry, transmission electron microscopy/ transmission electron diffraction, Raman scattering, and photoluminescence were employed to characterize the implanted layers. Two different types of the broad band emission extending over $0.75-1.1 \mathrm{eV}$ were observed in photoluminescence spectra of annealed samples. One of the bands disappears in photoluminescence spectra of samples annealed at $1100{ }^{\circ} \mathrm{C}$ unlike the other one.
\end{abstract}

DOI: $10.12693 /$ APhysPolA.125.1288

PACS: 61.80.-x, 61.72.Ff, 63.20.-e, 78.66.-w

\section{Introduction}

A new class of structures - quantum dots (QDs) has attracted great interest during the last two decades as they combine the advantages of bulk semiconductors with those of isolated atoms. Downsizing of electronic devices made the research of synthesis of self-assembled QDs directly in Si very promising. Because of confinement, it was expected that electrons in direct band gap QDs could occupy discrete energy levels, in a similar way as they do in atoms [1]. However, on moving from a bulk system to a dot system there arise several physical factors which control whether the interband transitions in a quantum dot will be direct or indirect. The first factor is quantum confinement effect which drives electron levels up and holes levels down in energy. The second factor is mechanical strains which can drive levels either up or down in energy. Moreover, the band alignment between QDs and surrounding matrix has to be kept in account. Finally, structural defects like dislocations that usually formed around the QDs in strained host matrix [2] could be more favorable for carrier recombination in comparison with band-to-band recombination inside QDs. Now it is already known that band line-ups of $\operatorname{InAs} / \mathrm{Si}, \mathrm{InSb} / \mathrm{Si}$ and $\mathrm{GaSb} / \mathrm{Si}$ are expected to be of type-II as indirect $\mathrm{Si}$ valleys lying lower in energy as a result of the upward energy shift and widening of the direct band-gap of $\mathrm{A}^{3} \mathrm{~B}^{5}$ QDs due to compressive stress [3-5]. Therefore, the radiative recombination in such systems is expected to be indirect both in real- and in $k$-spaces [4].

*corresponding author; e-mail: leibnits@gmail.com
In spite of it, these materials have gained significant technological interest in recent years due to their potential applications in mid-infrared optoelectronic devices. It was registered a broad band emission in the range of 0.75-1.1 eV in photoluminescence (PL) spectra of Si samples with embedded $\mathrm{A}^{3} \mathrm{~B}^{5}$ nanocrystals (NCs) created by MBE [3, 4] or by ion implantation [6-9].

In this paper we report on the direct formation of $\mathrm{A}^{3} \mathrm{~B}^{5}$ NCs in crystalline silicon by ion implantation followed by thermal treatment. The advantage of ion implantation technique is the areal and depth selectivity of phase formation in a substrate as well as its compatibility with industrial device production lines.

The aim of this work is to present our results on structural and optical characterization of " $\mathrm{Si}+\mathrm{A}^{3} \mathrm{~B}^{5}$ nanocrystals" system and discuss the effect of structural properties on efficiency and spectral peculiarities of photoluminescence.

\section{Experimental}

The specimens used for this study were prepared from lightly doped single crystalline $n$-type (100) Czochralski-grown silicon wafers with a resistivity of $4.5 \Omega / \mathrm{cm}$. The samples were implanted at $500{ }^{\circ} \mathrm{C}$ with V and III group ions in order to create supersaturated solution of implanted species in silicon. Subsequent annealing was used to restore crystalline structure of silicon matrix as well as to synthesize compound semiconductor $\mathrm{A}^{3} \mathrm{~B}^{5}$ phase in Si samples.

We performed three types of experiments differing in ion species.

In the first experiment $\mathrm{Si}$ samples were implanted firstly with As $\left(170 \mathrm{keV}, 3.2 \times 10^{16} \mathrm{~cm}^{-2}\right)$ and then with In $\left(250 \mathrm{keV}, 2.8 \times 10^{16} \mathrm{~cm}^{-2}\right)$ ions and subsequently annealed at $1050^{\circ} \mathrm{C}$ for $3 \mathrm{~min}$ in inert ambient. 
In the second experiment Si samples were implanted firstly with $\mathrm{Sb}(350 \mathrm{keV})$ and then with In $(350 \mathrm{keV})$ or $\mathrm{Ga}(250 \mathrm{keV})$ ions. The fluencies were $3.5 \times 10^{16} \mathrm{~cm}^{-2}$ or $5 \times 10^{16} \mathrm{~cm}^{-2}$ for both ion species in the case of $(\mathrm{Sb}+\mathrm{In})$ or $(\mathrm{Sb}+\mathrm{Ga})$ ion implantations, accordingly. Subsequently, implanted samples were annealed at 900$1100^{\circ} \mathrm{C}$ for $30 \mathrm{~s}-60 \mathrm{~min}$ in Ar ambient. The samples from the first two experiments were cooled to room temperature between implantation of different ions.

In the third experiment $\mathrm{Si}$ samples were implanted with $\mathrm{Ga}\left(250 \mathrm{keV}, 3.5 \times 10^{16} \mathrm{~cm}^{-2}\right)$ and $\mathrm{Sb}(350 \mathrm{keV}$, $\left.3.5 \times 10^{16} \mathrm{~cm}^{-2}\right)$ ions. The samples were stored in a chamber with constant temperature $T=500{ }^{\circ} \mathrm{C}$ between implantation of different ions. Afterwards, the samples were annealed at $1100^{\circ} \mathrm{C}$ for 3,30 , and $60 \mathrm{~min}$ in $\mathrm{Ar}$ ambient.

The structural properties of the samples were investigated using the Rutherford backscattering spectrometry (RBS) and transmission electron microscopy (TEM) and diffraction (TED). The RBS spectra were collected with a collimated $1.3-1.5 \mathrm{MeV} \mathrm{He}{ }^{+}$beam at a backscattering angle of $170^{\circ}$. TEM experiments were performed in plan-view geometry using a Hitachi H-800 instrument operating at $200 \mathrm{keV}$. The optical properties of samples were investigated by the Raman spectroscopy and low temperature PL spectroscopy. The Raman scattering (RS) spectra were recorded at room temperature in the backscattering geometry in the range from 90 to $600 \mathrm{~cm}^{-1}$ using a micro-Raman setup Nanofinder with excitation wavelength of $473 \mathrm{~nm}$. The PL spectra were recorded in the spectral region of $0.7-2 \mathrm{eV}$ using $600 \mathrm{~mm}$ grating monochromator in combination with a cooled to liquid nitrogen temperature InGaAs detector. During measurements the samples were immersed in a liquid helium cryostat and the $514.5 \mathrm{~nm}$ line of an argon ion laser was used to excite PL.

\section{Results and discussion}

Figure 1a shows the depth profiles of $\mathrm{Ga}$ and $\mathrm{Sb}$ atoms in Si samples simulated stopping and ranges of ions in matter(SRIM) and calculated from the experimental RBS spectra. These calculations do not take into account the implantation temperature. Therefore, the simulated results are close to experimental depth profiles of implanted species for room temperature implantation [10] only. The depth profiles were calculated from RBS spectra by fitting of the spectra using HEAD code until the simulated spectra coincided completely with the experimental spectra.

From Fig. 1a one can see that implantation at $500{ }^{\circ} \mathrm{C}$ already leads to strong broadening and significant reduction of the impurity concentration as compared to the SRIM calculation that could be explained by transient enhanced diffusion (TED). Figure $1 b$ presents the RBS spectra of the $(\mathrm{Sb}+\mathrm{In})$ implanted samples. One can see that high temperature annealing leads to further redistribution of impurity.
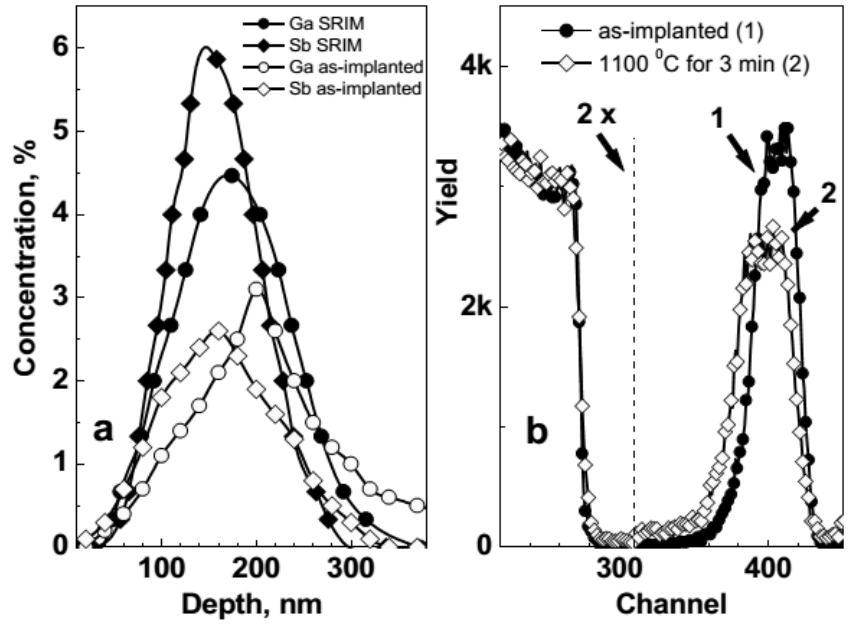

Fig. 1. Simulated (SRIM) and calculated from the RBS spectra (a) depth profiles of impurities in Si implanted with $\mathrm{Ga}\left(250 \mathrm{keV}, 3.5 \times 10^{16} \mathrm{~cm}^{-2}\right)$ and $\mathrm{Sb}$ $\left(350 \mathrm{keV}, 3.5 \times 10^{16} \mathrm{~cm}^{-2}\right)$ ions. RBS spectra (b) of Si samples implanted (1) with $\mathrm{Sb}(350 \mathrm{keV}, 3.5 \times$ $\left.10^{16} \mathrm{~cm}^{-2}\right)$ and In $\left(350 \mathrm{keV}, 3.5 \times 10^{16} \mathrm{~cm}^{-2}\right)$ ions and annealed at $1100{ }^{\circ} \mathrm{C}$ for $3 \min (2)$

The results of the TEM studies in plan-view mode are depicted in Fig. 2. One can observe faceted In As, InSb and $\mathrm{GaSb}$ nanoprecipitates in Si samples, implanted with $(\mathrm{As}+\mathrm{In}),(\mathrm{Sb}+\mathrm{In})$ and $(\mathrm{Ga}+\mathrm{Sb})$ ions, correspondingly. The crystalline nature and stoichiometry of InAs precipitates is proved by the presence of the Moire fringe patterns in the TEM images (inset in Fig. 2a) [7].

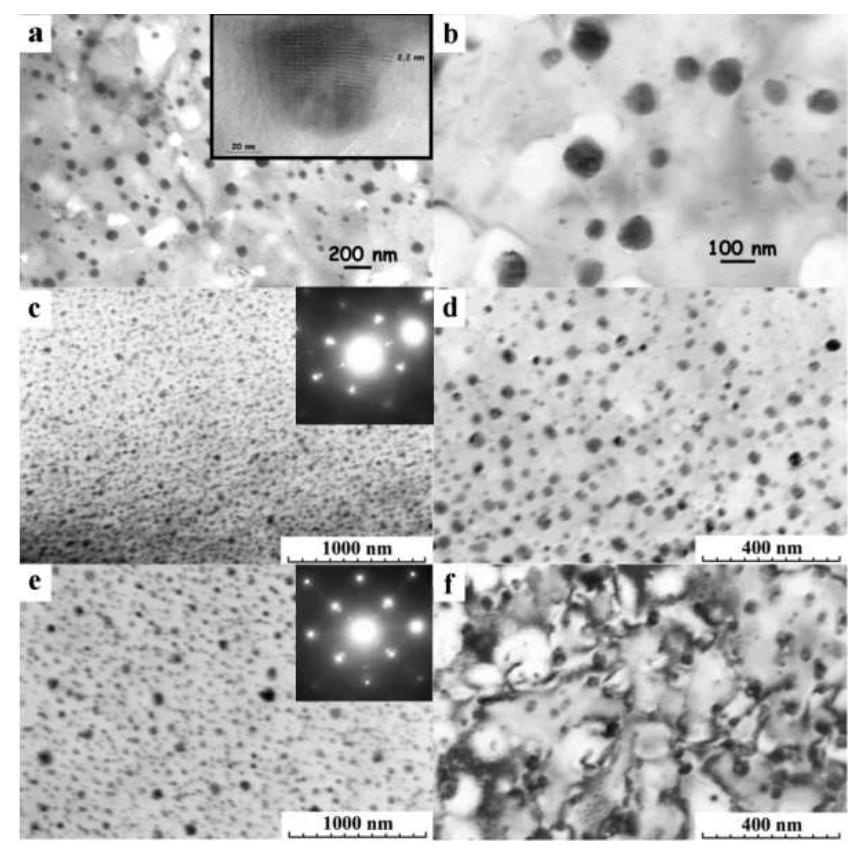

Fig. 2. Bright-field TEM images from Si samples after "hot" implantation of (As + In) (a), (b), (Sb + In) (c), (d), $(\mathrm{Ga}+\mathrm{Sb})(\mathrm{e}),(\mathrm{f})$ ions and annealing at $1050{ }^{\circ} \mathrm{C}$ for $3 \mathrm{~min}(\mathrm{a})$, (b) or $1100{ }^{\circ} \mathrm{C}$ for $30 \mathrm{~min}$ (c), (f). 
The presence of crystalline InSb and GaSb nanoprecipitates in annealed samples is proved by RS spectra (Fig. 3). Thus, a layer with $\mathrm{A}^{3} \mathrm{~B}^{5}$ crystallites is formed in the annealed samples. This layer is characterized by a good structural quality in the case of (As + In) implanted samples in contrast to heavily damaged layer of samples implanted with $(\mathrm{Sb}+\mathrm{In})$ or $(\mathrm{Ga}+\mathrm{Sb})$ ions. The surface layer with InSb or GaSb nanocrystals contains a lot of dislocation loops (Fig. 2f) and microtwins (inset in Fig. 2c,e). And indeed, we failed to get aligned RBS spectra of the $(\mathrm{Ga}+\mathrm{Sb})$ implanted and annealed sample while the aligned yield almost reach the random level (not shown) in the case of $(\mathrm{Sb}+\mathrm{In})$ sample. It indicates that the layer with InSb or GaSb nanocrystals is in near amorphous state even after $1100^{\circ} \mathrm{C}$ annealing.

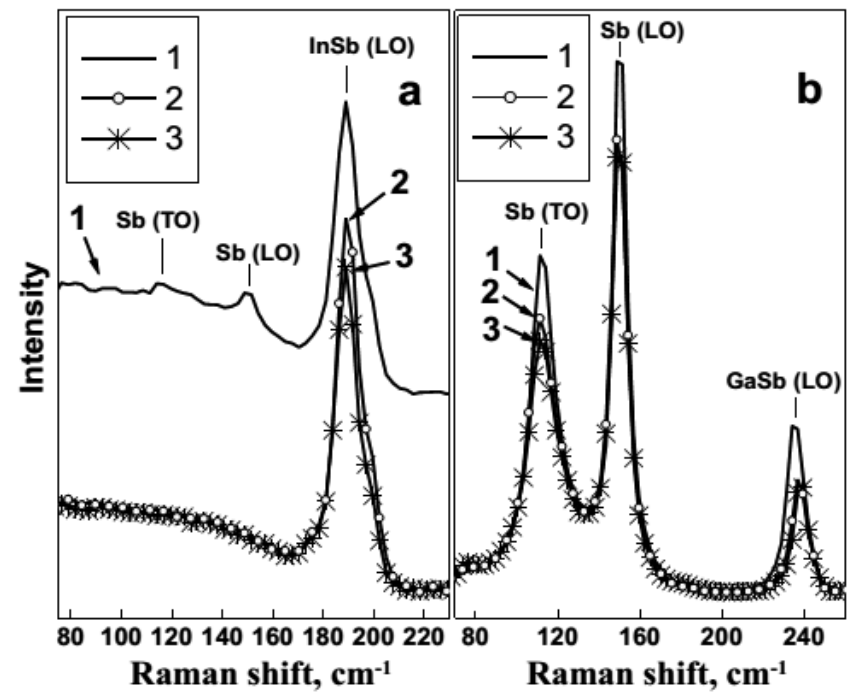

Fig. 3. RS spectra of $\mathrm{Si}$ samples implanted with $(\mathrm{Sb}+\mathrm{In})(\mathrm{a})$ or $(\mathrm{Ga}+\mathrm{Sb})(\mathrm{b})$ ions and annealed at $1100{ }^{\circ} \mathrm{C}$ for $3(1), 30(2)$ or 60 (3) min.

In order to identify nanocrystals RS was used. Figure 3 depicts RS spectra of implanted with $(\mathrm{Sb}+\mathrm{In})$ and $(\mathrm{Ga}+\mathrm{Sb})$ ions and annealed samples. The peaks at $189 \mathrm{~cm}^{-1}$ (Fig. 3a) and 235-237 $\mathrm{cm}^{-1}$ (Fig. 3b) should be attributed to LO-phonon scattering of crystalline InSb and GaSb, accordingly. It confirms the formation of $\mathrm{InSb}$ or GaSb nanocrystals in implanted layers of Si samples. Besides them, additional peaks at $115 \mathrm{~cm}^{-1}$ and $150 \mathrm{~cm}^{-1}$ present in RS spectrum (Fig. 3a) of the sample implanted with $(\mathrm{Sb}+\mathrm{In})$ ions and annealed at $1100^{\circ} \mathrm{C}$ for $3 \mathrm{~min}$. These peaks are the characteristic lines for crystalline Sb. For bulk Sb the frequencies of TO- and LO-phonons are 113 and $152 \mathrm{~cm}^{-1}$ [11], respectively. An increase of annealing duration up to 30-60 min results in disappearing of $\mathrm{Sb}$ lines. It indicates that $\mathrm{Sb}$ precipitates are present in $(\mathrm{Sb}+\mathrm{In})$ ion implanted sample after rapid thermal annealing (RTA) only. At the same time the characteristic bands for crystalline $\mathrm{Sb}$ are present in RS spectra of $(\mathrm{Ga}+\mathrm{Sb})$ implanted sample even after long time annealing at $1100^{\circ} \mathrm{C}$ (Fig. $3 \mathrm{~b}$ ).
In addition, a narrow peak at $518 \mathrm{~cm}^{-1}$ corresponding to zone-center phonons scattering of crystalline silicon is registered in RS spectra (not shown) of all discussed samples. The presence of this peak confirms the crystalline state of the silicon matrix. However, it should be noted that a significant shift towards low frequencies occurs in comparison with the peak's position at $521 \mathrm{~cm}^{-1}$ of undamaged Si [8]. This shift is caused by the presence of significant mechanical strains within the implanted layer [8].

Figure 4 depicts the PL spectra of implanted samples. The sharp lines at $1.09 \mathrm{eV}$ and $1.15 \mathrm{eV}$ are related to bound exciton phononless and phonon assisted recombination at main residual doping impurity (phosphorus) or implanted donor impurity (arsenic or antimony). Besides them, the broad band emission in the range of 0.8 $1.1 \mathrm{eV}$ dominates in the most of PL spectra. We could distinguish two types of the broad band depending on the type of implanted species. The band presented in PL spectra of samples implanted with $(\mathrm{As}(\mathrm{Sb})+\mathrm{In})$ ions are observable even after annealing at $1100^{\circ} \mathrm{C}$ for $60 \mathrm{~min}$ (Fig. 4b) and could be fitted as a superposition of at least two bands with maxima at $0.95 \mathrm{eV}$ and $0.99 \mathrm{eV}$. It has been previously reported on the observation of similar broad band in PL spectra of Si samples implanted with As $(\mathrm{Sb})$ and In ions and annealed by flash lamp annealing (FLA) [9], RTA [6] or conventional furnace annealing (FA) [7] at $900-1150^{\circ} \mathrm{C}$.

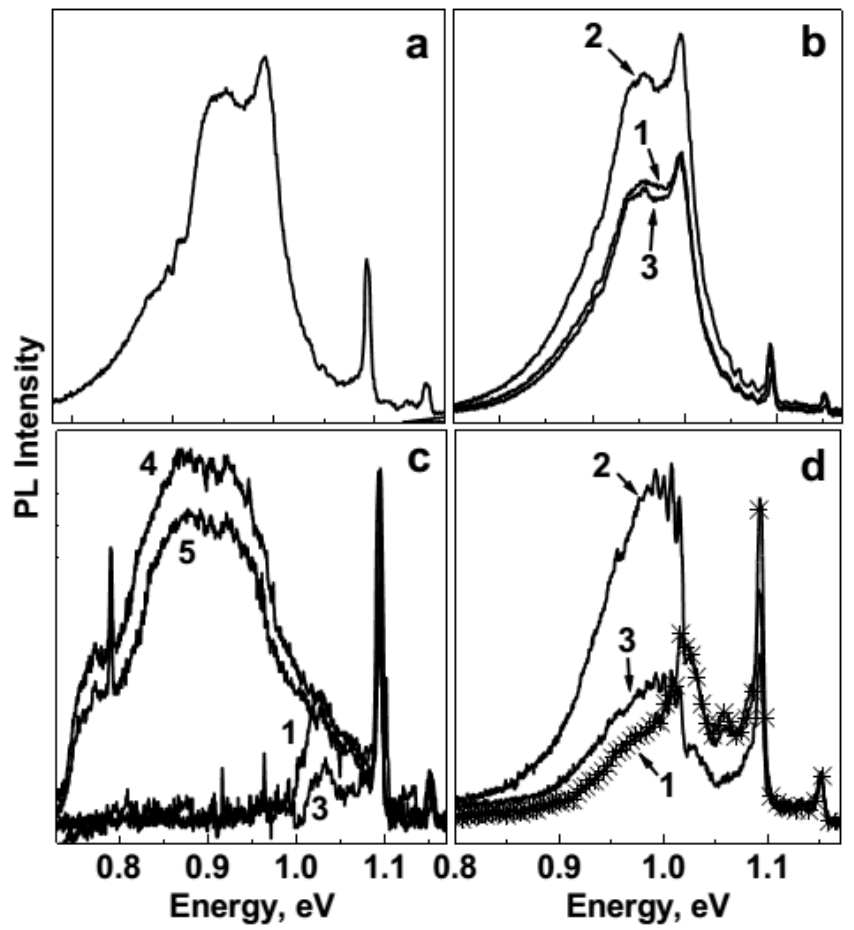

Fig. 4. PL spectra of $\mathrm{Si}$ samples implanted with $(\mathrm{As}+\mathrm{In})(\mathrm{a}),(\mathrm{Sb}+\mathrm{In})(\mathrm{b}),(\mathrm{Sb}+\mathrm{Ga})(\mathrm{c})$ or $(\mathrm{Ga}+\mathrm{Sb})(\mathrm{d})$ ions and annealed at $900(4,5), 1050(\mathrm{a})$ or $1100^{\circ} \mathrm{C}(1-3)$ for $30 \mathrm{~s}(4), 3 \mathrm{~min}(\mathrm{a}, 1), 30 \mathrm{~min}(2)$, $45 \min (5)$ or $60 \min (3)$. 
Moreover, a similar band was detected in the PL spectra of silicon samples with embedded InAs or InSb nanocrystals that were grown on $\mathrm{Si}(100)$ by solid-source MBE and annealed at $400^{\circ} \mathrm{C}$ [4]. It has been presumed [4] that radiative recombination of localized electrons at the inhomogeneous interfaces between $\mathrm{InAs}(\mathrm{InSb})$ and $\mathrm{Si}$ with quantum confined holes are responsible for the band appearance in PL spectra. The question about the nature of discussed band is still open and needs further investigations. At the same time the broad band with maximum near $0.9 \mathrm{eV}$ is registered in $\mathrm{PL}$ spectra of $(\mathrm{Sb}+\mathrm{Ga})$ ion implanted samples (Fig. 4c).

A similar band was observed earlier in the PL spectra of silicon samples with embedded tin $(\alpha-\mathrm{Sn})$ QDs in Ref. [12]. Sn QDs were formed in $\mathrm{Si}(100)$ as result of heat treatment up to $800^{\circ} \mathrm{C}$ of a few nanometer thick $\mathrm{Sn}_{x} \mathrm{Si}_{1-x}$ layers with $x \leq 0.1$ grown on $\mathrm{Si}$ surface. The appearance of this band was attributed to the presence of defects introduced by the grown layers.

In the experiment under consideration here, the similar band is registered in PL spectra of Si implanted with $\mathrm{Sb}$ and $\mathrm{Ga}$ ions. Thus, the question about the nature of this band arises. There are at least three possible explanations of near-IR photoluminescence origin for "Si $+\mathrm{SbGa}$ nanocrystals". They are: carrier recombination inside GaSb NCs, radiative recombination at the nanocrys$\mathrm{tal} / \mathrm{Si}$ matrix interfaces and dislocation-related luminescence [13]. After the annealing at $1100{ }^{\circ} \mathrm{C}$ the band at 0.75-1.1 eV disappears in the PL spectra (Fig. 4c). At the same time the PL spectra of $\mathrm{Si} / \mathrm{GaSb}$ samples annealed at $1100^{\circ} \mathrm{C}$ exhibit a series of relatively more sharp lines at successive line spacing of $8 \mathrm{meV}$ (Fig. 4d). The spectrum transformations could be related to annealing of a part of dislocation-type defects and is presently under study by our team.

\section{Conclusions}

We have investigated structural and optical properties of silicon layers with embedded InAs, InSb and GaSb nanocrystals formed by high fluence ion implantation at $500{ }^{\circ} \mathrm{C}$ followed by thermal treatment at $(900-$ $1100^{\circ} \mathrm{C}$ ) for $30 \mathrm{~s}-1 \mathrm{~h}$. A significant loss and redistributions of implanted species has been revealed by RBS experiment as a result of "hot" implantation conditions and post-implantation annealing. The formation of $\mathrm{A}^{3} \mathrm{~B}^{5}$ nanocrystals in implanted Si layer was registered in all annealed samples using TEM and RS experiments. In As $\mathrm{NCs}$ are formed in the Si near-surface layer of good structural quality, while the heavily damaged Si layer with $\mathrm{InSb}$ and $\mathrm{GaSb} \mathrm{NCs}$ contains a lot of dislocation loops and microtwins. Besides $\mathrm{A}^{3} \mathrm{~B}^{5} \mathrm{NCs}$, the Sb nanocrystals were registered in $\mathrm{Si}$ samples implanted with $(\mathrm{Sb}+\mathrm{In})$ or $(\mathrm{Ga}+\mathrm{Sb})$ ions and annealed at $1100^{\circ} \mathrm{C}$ for $3-60 \mathrm{~min}$.
Two different types of the broad bands in the range of 0.75-1.1 eV were detected in PL spectra of annealed samples. The first band was registered in PL spectra of $\mathrm{Si}$ samples implanted with (As ( $\mathrm{Sb})+\mathrm{In})$ ions and could be fitted as a superposition of at least two bands with maxima at $0.95 \mathrm{eV}$ and $0.99 \mathrm{eV}$. This broad band is observable in PL spectra of samples annealed even at $1100^{\circ} \mathrm{C}$ for $60 \mathrm{~min}$. In contrast to it the band with maximum near $0.9 \mathrm{eV}$ in $\mathrm{PL}$ spectra of $(\mathrm{Sb}+\mathrm{Ga})$ ion implanted samples are not visible after annealing at temperature as high as $1100^{\circ} \mathrm{C}$ for $3-60 \mathrm{~min}$.

\section{References}

[1] T. Mano, H. Fujioka, K. Ono, Y. Watanabe, M. Oshima, Appl. Surf. Sci. 130-132, 760 (1998).

[2] Y.-K. Huang, C.-P. Liu, Y.-L. Lai, C.-Y. Wang, Y.-F. Lai, H.-C. Chung, Appl. Phys. Lett. 91, 091921 (2007).

[3] R. Heitz, N.N. Ledentsov, D. Bimberg, A.Yu. Egorov, M.V. Maximov, V.M. Ustinov, A.E. Zhukov, Zh.I. Alferov, G.E. Cirlin, I.P. Soshnikov, N.D. Zakharov, P. Werner, U. Gosele, Physica E 7, 317 (2000).

[4] M. Jo, K. Ishida, K. Kawamoto, S. Fukatsu, Phys. Status Solidi C 0, 1117 (2003).

[5] S. Prucnal, S. Facsko, C. Baumgart, H. Schmidt, M.O. Liedke, L. Rebohle, A. Shalimov, H. Reuther, A. Kanjilal, A. Mucklich, M. Helm, J. Zuk, W. Skorupa, Nanoletters 11, 2814 (2011).

[6] A.L. Tchebotareva, J.L. Brebner, S. Roorda, C.W. White, Nucl. Instrum. Methods Phys. Res. B 175-177, 187 (2001).

[7] F. Komarov, L. Vlasukova, W. Wesch, A. Kamarou, O. Milchanin, S. Grechnyi, A. Mudryi, A. Ivankovich, Nucl. Instrum. Methods Phys. Res. B 266, 3557 (2008).

[8] F. Komarov, L. Vlasukova, O. Milchanin, A. Mudryi, B. Dunets, W. Wesch, E. Wendler, Phys. Status Solidi A 209, 148 (2012).

[9] S. Prucnal, M. Turek, A. Drozdziel, K. Pyszniak, A. Wojtowicz, S.-Q. Zhou, A. Kanjilal, A. Shalimov, W. Skorupa, J. Zuk, Cent. Eur. J. Phys. 9, 338 (2011).

[10] F.F. Komarov, O.V. Milchanin, L.A. Vlasukova, W. Wesch, A.F. Komarov, A.V. Mudryi, Bull. Russ. Acad. Sci., Phys. 74, 252 (2010).

[11] M. Landolt, J. Bornstein, Series Numerical Data and Fuctional Relationships in Science and Technology, Springer-Verlag, Berlin 1989.

[12] A. Karim, G.V. Hansson, W.-X. Ni, P.O. Holtz, M. Larsson, H.A. Atwater, Opt. Mater. 27, 836 (2005).

[13] F. Komarov, L. Vlasukova, O. Milchanin, A. Mudryi, J. Zuk, K. Pyszniak, M. Kulic, Acta Phys. Pol. A 120, 204 (2011). 